\title{
Efectividad del tratamiento corto con penicilina en faringitis aguda
}

Penicillin for acute sore throat: randomized double blind trial of seven days versus three days treatment or placebo in adults. Zwart S., Sachs A. P. E., Ruijs G. J. H. M., Gubbels J. W., Hoes A. W., De Melker R. A. BMJ 2000; 320:150 -4.

\section{Objetivo}

Determinar la eficacia del tratamiento de tres días con penicilina comparado con el tratamiento de 7 días y con placebo para la faringitis en adultos.

\section{Diseño}

Estudio randomizado, doble ciego, placebo control, con seis meses de seguimiento entre 1994 y 1996.

\section{Lugar}

Se realizó en 43 centros de atención ambulatoria en Los Países Bajos.

\section{Pacientes}

Se evaluaron 561 pacientes, de 15 a 60 años, con odinofagia de aparición aguda (7 días o menos).

\section{Intervención}

Los pacientes recibieron 3 esquemas diferentes de tratamiento: Penicilina V por 7 días (grupo 1), penicilina V por 3 días seguida por 4 días de placebo (grupo 2) o placebo por 7 días (grupo 3). La dosis fue 250 mg. cada 8 hs.

\section{Medición de resultados principales}

Al ingreso y al final del tratamiento se realizó un hisopado de fauces y cultivo. Se realizó un registro diario de la odinofagia, del grado de dificultad para desempeñar sus tareas habituales, de la temperatura oral, del numero de analgésicos diarios usados. Se los reexaminó a los 14 días y se los contactó por teléfono a los 2, 4 y 6 meses, para interrogarlos sobre reaparición de odinofagia, aparición de tos, rinorrea u otalgia, recurrencias o complicaciones.

\begin{tabular}{|c|c|c|c|}
\hline \multicolumn{4}{|c|}{$\begin{array}{l}\text { Resultados principales } \\
\text { Evolución en los } 3 \text { grupos }\end{array}$} \\
\hline \multirow[t]{2}{*}{ Variables evaluadas } & \multicolumn{3}{|c|}{ Grupos } \\
\hline & $\begin{array}{l}7 \text { días } \\
\text { (grupo 1) }\end{array}$ & $\begin{array}{l}3 \text { días } \\
\text { (grupo 2) }\end{array}$ & $\begin{array}{l}\text { Placebo } \\
\text { (grupo 3) }\end{array}$ \\
\hline Resolución de síntomas & - & $\begin{array}{l}1.9 \text { días después que } \\
\text { grupo } 1(p<0.001)\end{array}$ & $\begin{array}{l}1.7 \text { días despues que } \\
\text { grupo } 1(p<0.001)\end{array}$ \\
\hline $\begin{array}{l}\text { Reinicio de actividad } \\
\text { diaria }\end{array}$ & - & $\begin{array}{l}2.2 \text { días después que } \\
\text { grupo } 1\end{array}$ & $\begin{array}{l}2 \text { días después que } \\
\text { grupo } 1\end{array}$ \\
\hline $\begin{array}{l}\text { Complicaciones } \\
\text { supurativas }\end{array}$ & $2 \%$ & $4 \%$ & $13 \%$ \\
\hline $\begin{array}{l}\text { Respuesta bacterioló- } \\
\text { gica (erradicación del } \\
\text { S. grupo A) }\end{array}$ & $\begin{array}{c}72 \% \\
(p<0.05)\end{array}$ & $41 \%(p<0.05)$ & $7 \%$ \\
\hline
\end{tabular}

S. grupo A)

\section{S. grupo A : Streptococcus grupo A}

Durante los primeros 3 días la resolución de síntomas fue similar en el grupo 1 y 2.

En el grupo 1 hubo 5\% de recurrencia y en el grupo de 2 hubo 40\% de recurrencia.

Los analgésicos utilizados en el grupo 1, al séptimo día declinaron de $61 \%$ a $5 \%$, con diferencias significativas con los otros 2 grupos.

En el grupo 3 hubo 6 pacientes con complicaciones supurativas lo que obligó a iniciar el tratamiento antibiótico.

El $78.8 \%$ tenia cultivo positivo basal para Streptococcus.

\section{Conclusiones}

Este trabajo demuestra que el tratamiento por 7 días con penicilina $V$ en adultos con faringitis por Streptococcus grupo A es más efectivo que 3 días o placebo, en reducir la duración de los sintomas y las complicaciones supurativas y en mejorar la repuesta bacteriológica.

Fuente de financiamiento: Groene Land Health Insurances (Achmea Group) And The Stiching Gezondheidszorgonderzock Ysselmond In Zwolle, Netherlans (Los Países Bajos).

\section{COMENTARIO}

Este estudio demuestra que el tratamiento por 7 días con penicilina $V$ en adultos con faringitis por Streptococcus grupo A es el más efectivo en reducir la duración de los síntomas y las complicaciones supurativas y también es el más efectivo en la respuesta bacteriológica.

La evidencia disponible hasta ahora no son suficientes para recomendar acortar el tratamiento de 10 a 7 días. Asimismo las sociedades científicas internacionales basadas en la evidencia disponible sugieren realizar el tratamiento con penicilina por 10 días. ${ }^{1}$

La Sociedad Americana de Enfermedades Infecciosas (I.D.S.A.) confeccionó guías en 1997 con el objetivo de prevenir la fiebre reumática y las complicaciones supurativas, reducir los signos, síntomas, el contagio de Streptococcus grupo A y los efectos adversos del tratamiento. ${ }^{1}$ Esta sociedad recomienda como tratamiento de elección: penicilina $V$ oral por 10 días o benzatínica en monodosis.

El uso de cefalosporinas de primera o segunda generación también a resultado efectivo, pero se debe tener en cuenta que estos antibióticos generan presión de selección, aumentando la resistencia bacteriana, por lo que se desaconseja su utilización. ${ }^{1}$

Un metaanalisis publicado en febrero de 2000 demostró que es más efectivo el tratamiento con penicilina o aminopenicilinas $\mathrm{c} / 12 \mathrm{hs}$. que $\mathrm{c} / 24 \mathrm{hs.}{ }^{2}$ Según recomendación de la 0.M.S. la mejor opción es iniciar el tratamiento con el diagnóstico bacteriológico confirmado, debido a que la faringitis estreptococcica no se presenta siempre en forma típica, y así se evita el uso inadecuado de antibióticos generando resistencia bacteriana. ${ }^{3}$
Teniendo en cuenta que es posible esperar a iniciar el tratamiento hasta 9 días, sin aumentar el riesgo de fiebre reumática ${ }^{1}$, se han desarrollado scores que estratifican a las variables clínicas en tres categorias de probabilidad: alta ( 3 o más criterios), intermedia ( 2 criterios) y baja (menos de 2 criterios). 4 En la Argentina, el valor predictivo positivo de esta regla de predicción es $62 \%$, considerando que la prevalencia es entre 20 y $25 \%$.

En mayores de 2 años con alta probabilidad se recomienda iniciar tratamiento de inmediato, sin esperar el cultivo. En pacientes con probabilidad intermedia hacer test rápido, y si esto no es posible o es difícil el seguimiento, iniciar el tratamiento. En pacientes con probabilidad baja, hacer cultivo y diferir el tratamiento hasta tener el resultado. ${ }^{4}$

La recomendación final es ante todo caso de faringitis aguda, evaluar la probabilidad clínica de etiología estreptococcica, realizar un método de estudio microbiológico y proceder de acuerdo a lo mencionado mas arriba según score de probabilidad. Siempre que el resultado microbiológico sea negativo se debe suspender el antibiótico.

Para el tratamiento en no alérgicos indicar penicilina oral por 10 días y en alérgicos eritromicina.

Las dosis orales recomendadas son: para niños, penicilina $\vee 250 \mathrm{mg}$. c/812 hs. (A-II)* ${ }^{*}$, para adolescentes y adultos, $250-500 \mathrm{mg} . \mathrm{c} / 6-8 \mathrm{hs}$. (A-II). Eritromicina 20-40 mg./kg./d. c/8-12 hs., máximo 1000 mg./d. (A-II). ${ }^{1}$ * Buena evidencia para recomendarlo

\section{Dr. Victor D. Rosenthal.} Especialista En Medicina Interna y en Enfermedades Infecciosas.

2. Andrew J. Lan, MPH*, John M. Colford, and Jr, MD, PhD. The Impact of Dosing Frequency on the Efficacy of 10-Day Penicillin or Amoxicillin Therapy for Streptococcal Tonsillopharyngitis: A Metaanalysis. Pediatrics. 2000; 105 (2): 19-26.

3. Kaplan FL. Clinical Guidelines For Group A Streptococcal Throat Infections. Department Of Pediatrics, WORLD HEALTH ORGANZATION Collaborating Center For Reference And Research On Streptococci, University Of Minnesota Medical School, Minneapolis Lancet 1997; 350 (9082): 899-900 